\title{
Quando as Demandas Protecionistas Falam Mais Alto. Mitos e Fatos Sobre a Crise que Atingiu o Mercosul em 1999
}

\author{
Morgana Corrêa Campos Alves \\ Márcio Bobik Braga*
}

Resumo: 0 artigo mostra que a desvalorização do real em 1999 afetou negativamente as relações comerciais entre Brasil e Argentina, impulsionando antigas demandas protecionistas. De forma geral, os números do comércio bilateral comprovam que a temida invasão de produtos brasileiros ao mercado argentino nunca se concretizou. Entretanto, a ausência de regras claras e de uma institucionalização de fato para 0 Mercosul abriu espaço para a utilização de medidas de anti-dumping e tentativas de adoção de salvaguardas dentro do bloco. Tais medidas ajudaram a reduzir o comércio bilateral, que sentiu também os efeitos da crise que se instalou na região. Através das análises de jornais brasileiros e argentinos, o artigo mostra ainda que empresários e políticos de ambos os países travaram uma guerra de acusações e ameaças, que dificultaram as negociações setoriais em andamento e colocaram em dúvida a viabilidade do Mercosul.

Palavras-chaves: Câmbio, Comércio, Mercosul, Protecionismo, Crise.

Abstract: This article shows that the real's devaluation in 1999 has adversely affected trade relations between Brazil and Argentina, inciting old protectionist demands. In a general way, the official numbers for bilateral trade prove that a feared invasion of Brazilian products into the Argentine market has never materialized. However, one can verify that the absence of clear rules and de facto institutionalization for the Mercosur has paved the way for the use of anti-dumping measures and attempts at adopting safeguard measures within the bloc. Such measures helped reduce bilateral trade, which was also hit by the crisis that struck the region. The analysis of Brazilian and Argentine newspapers also shows that entrepreneurs and politicians from both countries waged a war of accusations and threats, thus hampering industry-to-industry negotiations in progress and putting Mercosur's viability in jeopardy.

Keywords: Currency, Mercosur, Protectionism, Trade, Crisis.

* Morgana Corrêa Campos Alves, Graduada em jornalismo pela Escola de Comunicações e Artes da Universidade de São Paulo e mestre em América Latina pelo Programa de Pós-Graduação em Integração da América Latina da Universidade de São Paulo. E-mail: morganacampos13@yahoo.com.br. Márcio Bobik Braga, Professor Livre-Docente do Depto. de Economia da Faculdade de Economia, Administração e Contabilidade da Universidade de São Paulo, campus de Ribeirão Preto e do Programa de Pós-graduação em Integração da América Latina da Universidade de São Paulo. E-mail: marbobik@ usp.br. Recebido em 03/12/06 e aceito em 14/12/07. 


\section{Introdução}

A maxidesvalorização cambial enfrentada pelo Brasil em 1999 não apenas redefiniu os rumos do Plano Real, como também desencadeou uma das mais graves crises institucionais dentro do Mercado Comum do Sul (Mercosul), colocando em confronto direto as duas principais economias do bloco: Brasil e Argentina.

Afinal, as estruturas produtivas relativamente integradas, e que outrora eram comemoradas como símbolo de avanço do bloco, agora se apresentavam como uma ameaça para os produtores argentinos, que viam no real enfraquecido uma vantagem decisiva em favor de seus concorrentes do outro lado da fronteira.

Do ponto de vista brasileiro, a prioridade era evitar que o Plano Real naufragasse de uma vez, levando com ele o controle da inflação e a relativa estabilidade da economia. Sobrava assim pouco espaço (ou disposição) para concessóes que pudessem pelo menos tranqüilizar os parceiros regionais.

Para dificultar ainda mais as negociaçóes, o governo argentino encontravase suscetível a acatar demandas protecionistas, em meio à proximidade do período eleitoral. Além disso, o bloco sentia o peso de não ter "feito sua lição de casa", vendo-se agora diante de uma grave crise sem ainda dispor de mecanismos que pudessem ser acionados para compensar possíveis vantagens momentâneas, como o ganho cambial que os produtores brasileiros estavam prestes a desfrutar.

Apesar de toda histeria e das trocas de acusaçóes travadas nas páginas dos principais periódicos argentinos e brasileiros, a temida invasão de produtos brasileiros ao mercado argentino nunca se concretizou. Em parte, devido à própria desestabilização da cadeia produtiva brasileira, com as empresas se adaptando ao maior custo dos insumos importados e às dificuldades para obtenção de crédito, por exemplo. O comércio bilateral, no entanto, sentiu os efeitos negativos da grave crise econômica que atingiu os dois países e ajudou a deprimir o poder de compra de seus cidadãos. Além disso, as sucessivas barreiras técnicas, sanitárias e burocráticas, sem falar nas cotas e até salvaguarda, sem dúvida contribuíram para reduzir as trocas bilaterais, mesmo que temporariamente.

Mais do que corrente de comércio, no entanto, o que se perdeu com a crise 
de 1999 foi capital político, já que autoridades e líderes setoriais precisaram se desdobrar para conter ou manobrar demandas protecionistas, ao invés de negociarem o aprofundamento do bloco. Por outro lado, o Mercosul deu uma grande prova de solidez, com as decisóes do Tribunal Arbitral ou pelo simples fato dos empresários continuarem na mesa de negociação, mesmo quando os governos pareciam não se entenderem.

O objetivo principal deste artigo consiste em analisar as implicações para o Mercosul da desvalorização cambial ocorrida no Brasil em 1999, dando destaque aos movimentos protecionistas que ocorreram na época. Serão examinados os dados gerais da balança comercial bilateral, bem como os números dos setores considerados mais sensíveis. Também servirão de material de pesquisa os relatórios e laudos arbitrais, assim como as notícias e artigos publicados nos jornais Gazeta Mercantil e La Nación, como forma de se tentar resgatar parte do clima de disputa política daquele período.

\section{Volatilidade cambial e comércio}

A particularidade das relaçóes financeiras internacionais nos últimos tempos e a conjuntura das crises cambiais dos anos 90 intensificou o debate em torno dos regimes cambiais. ${ }^{1}$ Os defensores do regime de câmbio fixo têm destacado, além dos benefícios macroeconômicos decorrentes de uma inflação baixa, o argumento de que a volatilidade cambial prejudica o comércio internacional. Além da elevação nos custos de transação, esses defensores enfatizam as incertezas decorrentes da instabilidade cambial: quanto maior esta incerteza, maiores as dificuldades no cálculo dos preços relevantes aos resultados previstos nos contratos que envolvem as atividades comerciais. Como conseqüência, maior tende a ser a possibilidade de rompimento destes contratos. Ou seja, diante da incerteza quanto ao comportamento da taxa de câmbio, tem-se uma elevação na incompletude dos contratos que envolvem as transaçóes internacionais, o que tende a diminuir os incentivos na formalização destes contratos, desestimulando assim o comércio internacional. Em casos extremos e de longa duração, a volatilidade cambial tende a dificultar a reestruturação produtiva em favor

\footnotetext{
${ }^{1}$ Sobre este debate, ver Wise (2001). Este texto é também uma introdução a uma coletânea de artigos que tratam das crises cambiais na América Latina.
} 
das atividades relacionadas com o comércio internacional. ${ }^{2}$

Existe um outro argumento que reforça a relação inversa entre instabilidade cambial e comércio e que é particularmente importante em acordos bilaterais ou regionais: mudanças cambiais muito intensas tendem a provocar elevaçóes nas demandas por protecionismo no país que experimenta a valorização de sua moeda. ${ }^{3}$ A explicação para isto decorre do fato da volatilidade alterar a competitividade das empresas cujas atividades estão voltadas para a produção de bens comercializáveis. Ou seja, quando ocorre uma forte valorização da moeda doméstica, as perspectivas de intensificação das importações acabam levando empresas a demandar medidas protecionistas junto à autoridade econômica. O predomínio político dessas "vozes protecionistas" decorre do fato das empresas exportadoras e nacionais que produzem bens comercializáveis terem um maior poder político frente às empresas importadoras, ou por serem em maior número, ou por privilegiarem a produção nacional (apoio político, apoio dos sindicatos nacionais, apelo nacionalista etc.). Neste sentido, quando ocorre uma valorização da moeda doméstica, apesar da sociedade ganhar com a importação de produtos mais baratos, prevalecem as pressóes dos grupos que perdem com esta valorização.

Se estas conjecturas são verdadeiras, a relação entre protecionismo e mudanças cambiais abruptas, ou de uma forma mais geral a relação entre instabilidade cambial e comércio implica, no caso de um acordo regional, em um retrocesso no processo de integração econômica. O Mercosul parece ser um caso interessante a ser discutido diante da forte desvalorização da moeda brasileira ocorrida no início de 1999 . O protecionismo a ser esperado, evidentemente, era por parte do país que experimentou a valorização de sua moeda frente ao real: a Argentina.

\section{Os mitos da invasão comercial e da transferência de empresas}

Mesmo diante da falta de unanimidade quanto aos efeitos do câmbio sobre o comércio, é fato que as trocas entre Brasil e Argentina sempre ficaram suscetíveis às oscilações cambiais, seja pela inversão dos sinais dos saldos do

\footnotetext{
${ }^{2}$ Ver, por exemplo, International Monetary Fund (1984), Côté (1994), Eichengreen (1998) e Dell'ariccia (1999).

${ }^{3}$ Sobre este ponto, ver International Monetary Fund (1984) e Eichengreen (1998).
} 
comércio bilateral ou pela forte pressão dos lobbies setoriais por medidas protecionistas. Vale lembrar que as oscilaçóes cambiais quase sempre foram apenas a parte mais visível da adoção de políticas macroeconômicas diferenciadas nos dois países, com efeitos distintos sobre renda nacional e comércio regional.

(...) el hecho de que los dos principales socios del Mercosur hubieran encarado ambiciosos procesos de reforma comercial y estabilización macroeconómica con algún defasaje temporal entre si (Argentina realizaba la parte sustancial de esta tarea durante el bienio 1991-1992, al tiempo que Brasil lo hacia entre 1994 e mediados de 1995) y en forma contemporánea al progreso del programa de desgravación arancelaria intrarregional, se tradujo en cíclicas alteraciones en la paridad cambiaria bilateral efectiva. Este hecho generó diferente tipo de situaciones, que tuvieran impactos (positivos e negativos) sobre la consistencia macroeconómica de los respectivos programas de ajuste, afectando también a algunos de los sectores comercialmente más sensibles al comercio intraregional del país cuya moneda se apreciaba respecto de su socio regional (ROZEMBERG, SVARZMAN, 2002, p. 2).

O Plano de Conversibilidade da Argentina, que estabeleceu a paridade entre um peso e um dólar a partir de 1991, estabilizou o peso argentino e praticamente eliminou a inflaçáo, o que ajudou a estimular a demanda interna. Às custas, no entanto, de uma moeda sobrevalorizada, num momento em que a economia brasileira encontrava-se enfraquecida. De acordo com o anuário estatístico de 2004 da Comissão Econômica para América Latina e Caribe (CEPAL), enquanto a Argentina ostentava taxa anual de crescimento do Produto Interno Bruto (PIB) de 10,6\% (a preços constantes de 1995) em 1991 e de 9,6\% em 1992, a economia brasileira mostrava expansão de 1\% em 1991 e retração de 0,3\% em 1992.

Não tardou para que a balança comercial desequilibrasse em favor do Brasil. Segundo dados da Secretaria de Comércio Exterior do Brasil (SECEX), o Brasil registrou superávit comercial com a Argentina de US\$1,308 bilhão em 1992, após ter obtido saldos negativos de US\$ 133,124 milhóes em 1991 e de US\$ 754 milhões em 1990. Com isso, cresceram na Argentina as 
demandas por aplicação de medidas restritivas e de proteção.

Em 1994, no entanto, o cenário se inverte, em meio à implementação do Plano Real, que estabilizou a economia brasileira, porém também se apoiando num real fortalecido em relação ao dólar. Com recessão na Argentina e recuperação da atividade interna no Brasil, as exportações argentinas para o País cresceram 52,69\% em 1995. De acordo com a CEPAL, a economia argentina registrou contração de 2,9\% em 1995, enquanto a brasileira cresceu 4,2\%. Depois disto, as duas economias passaram por três anos de crescimento simultâneo, impulsionando o comércio regional. Em 1996, o PIB argentino teve avanço de 5,5\%; em 1997, de 8\%; e em 1998, de 3,8\%. Para o Brasil, as taxas foram de $2,5 \%, 3,1 \%$, e $0,2 \%$, respectivamente.

A desvalorização do real em 13 de janeiro de 1999, com implementação do câmbio flutuante dois dias depois, não trouxe, no entanto, resultados tão lineares como nos episódios anteriores. É verdade que a corrente entre Brasil e Argentina em 1999 caiu para US\$ 11,176 bilhóes, segundo dados da SECEX, após dois anos de fluxo praticamente estabilizado em um patamar próximo dos US\$ 15 bilhóes. Mas a temida invasão de produtos brasileiros nunca chegou de fato a ocorrer. Mesmo com a desvalorização do real, a Argentina ostentou superávit de US\$ 448,43 milhões em 1999, o que representava sim um acentuado declínio em relação aos US\$ 1,275 bilhão do ano anterior.

Para Rozemberg e Svarzman (2002), os conflitos comerciais que atingiram o Mercosul entre o final de 1998 e o primeiro trimestre de 2000, com pico das disputas em 1999, tiveram como pano de fundo não apenas a questão cambial, estando na verdade vinculados a questóes estritamente conjunturais. Entre os problemas, os autores destacam:

a) a forte e simultânea contração na demanda interna nos quatro países do bloco e, por conseqüência, a redução dos mercados potenciais da região; e b) a queda drástica dos preços internacionais das commodities, o que teve impacto direto na rentabilidade das exportaçóes para outros mercados, já que as economias da região são basicamente exportadoras de matérias-primas.

Tais fatores negativos, lembram os pesquisadores, foram potencializados no período pelo fato de que o regime de adequação (criado pela Decisão 24/94, que deu sobrevida à proteção tarifária nacional dentro do bloco para 
alguns produtores) ter chegado ao fim em dezembro de 1998 para Brasil e Argentina (Paraguai e Uruguai tinham até dezembro de 1999 como prazo). Ou seja, no início de 1999 o Mercosul havia eliminado definitivamente as tarifas residuais para praticamente todos os produtos no comércio entre Brasil e Argentina (o setor automotivo e o açucareiro permaneciam entre as poucas exceçóes), sem ainda existir um marco jurídico e institucional plenamente estabelecido no Mercosul.

Opinião semelhante é apresentada pelo embaixador Luiz Felipe de Seixas Corrêa, que classifica o ano de 1999 como o momento mais difícil para a integração regional desde a assinatura do Tratado de Assunção. Entre os fatores negativos que por si só já dificultariam as negociações em 1999, Corrêa (2000) destaca: o esgotamento da etapa inicial de incremento na corrente de comércio somente pela redução tarifária ("ganhos fáceis”); complexa agenda de negociaçóes, com aprofundamento da União Aduaneira; retração econômica nas duas maiores economias do bloco; e o fim do regime de adequação.

De qualquer forma, os lobbies setoriais viram na desvalorização a justificativa para a adoção de medidas protecionistas em disputas comerciais que se arrastavam há anos. Num primeiro momento, a principal preocupação do governo argentino era assegurar à população, empresários e investidores que nada mudava em relação à balança comercial e ao regime de conversibilidade, que corria o risco de ruir junto com a crise do real.

Especialistas e empresários, no entanto, se revezavam na mídia, alertando para a invasão de produtos brasileiros e criticando o fato de o Brasil não ter avisado às autoridades argentinas sobre a decisão de desvalorizar. Tornou-se recorrente na mídia argentina a expressão "Brasil Dependência”, em referência ao fato de que cerca de $30 \%$ das exportaçóes argentinas destinavam-se ao Brasil. A expressão simbolizava tanto o temor de que qualquer turbulência no Brasil teria efeitos negativos para a Argentina, quanto a preocupação com o fato da Argentina não ter o mesmo peso comercial para o Brasil, o que aparentemente náo colocava o país vizinho entre as prioridades das autoridades brasileiras.

Em 14 de janeiro, o jornal La Nácion publicou o texto "Exportaciones entre sombras", no qual exportadores e importadores argentinos manifestavam 
visóes diferentes sobre qual seria o impacto da desvalorização brasileira na balança comercial bilateral.

Los exportadores locales creen que el efecto será directo en las ventas argentinas a Brasil, que serán para el importador brasileño un $9 \%$ más caras. Para los importadores no habrá una avalancha de productos brasileños. Creen que la devaluación se trasladará rápidamente a los costos de producción, por lo que no crecerá la presión de los productos de ese país por entrar en la Argentina a precios más baratos. "Ya habrá algún industrial que diga que se viene la avalancha brasileña, pero esta no es una devaluación competitiva”, dijo Diego Pérez Santisteban, presidente de la Cámara de Importadores (ILLIANO, 1999).

Em 17 de janeiro, outra matéria do La Nación assegurava que em mais alguns dias as lojas argentinas ostentariam em suas vitrines produtos até $20 \%$ mais baratos com o selo "made in Brazil" e dava voz aos receios de invasão de produtos. "'Hay un riesgo muy alto: que nos inunde Brasil con sus productos', coincidieron Guillermo Gotelli, CEO y vicepresidente de Alpargatas, y Alberto Alvarez Gaiani, presidente de la Unión Industrial Argentina (UIA)" (SARALEGUI, 1999), diz a matéria. Gotelli advertiu ainda no mesmo texto:

Este es el momento para que el gobierno argentino aproveche su reputación para tomar medidas acordes a esta situación extrema. No quiero usar la mala palabra de la protección, pero sí habrá que cuidar el saldo comercial. Como nadie en el exterior quiere financiar el consumo de los argentinos, por algún camino se debe corregir el régimen de la balanza comercial (SARALEGUI, 1999).

Inicialmente, as autoridades argentinas adotaram um tom conciliador até por não restar outro caminho, já que a prioridade do Brasil era conter a crise interna e evitar o retorno da hiperinflação. "A desvalorização da moeda brasileira não está orientada a modificar a competitividade do país e sim para enfrentar um ataque especulativo ao real" (ALMEIDA, RIGGI, 1999), declarava o então ministro da Economia da Argentina, Roque Fernandéz. Ele 
garantia ainda que seu país não iria adotar qualquer medida protecionista, com o intuito de compensar a queda do real.

As palavras do entáo sub-secretário de Relaçóes econômicas Internacionais da Argentina, Jorge Campbell, seguiam a mesma linha:

Me parece políticamente inadecuado y técnicamente apresurado hablar de esas cosas. Lo único que hay hasta ahora es una modificación del tipo de cambio nominal. Y creo que va a llevar un tiempo, que estimo en un mínimo de 45 días, para ver cuál es el punto de equilibrio que Brasil encuentra, en el escenario más optimista (LA NACIÓN, 1999).

Sem dúvidas, muitos aspectos precisavam ser analisados, antes de se pensar em qualquer medida protecionista. Afinal, não havia garantias de que a vantagem cambial fosse, de fato, converter-se em ganho na balança cambial. Isso dependeria, entre outros fatores, de como as duas economias se comportariam - o fator renda - e mesmo do impacto que as incertezas teriam sobre os exportadores brasileiros: em qual patamar o real iria se estabilizar em relação ao dólar e qual efeito esse novo patamar cambial teria sobre inflação e custos de produção, por exemplo. Além disso, os exportadores brasileiros enfrentariam ainda dificuldades na obtenção de crédito, na administração de suas dívidas em dólares e maiores custos para importação de insumos.

De acordo com dados da SECEX, as exportaçóes brasileiras para a Argentina declinaram 20,51\% em 1999, totalizando US\$ 5,364 bilhóes, enquanto as importaçóes recuaram $27,56 \%$ para US\$ 5,812 bilhóes. Em 1999, o PIB brasileiro cresceu apenas 0,9\%, de acordo com estimativas da CEPAL, enquanto na Argentina a economia sofreu retração de 3,4\% em 1999.

O relatório de 1999 da Comissão Nacional de Comércio Exterior (CNCE) da Argentina chama a atenção para a importância desse fator renda. $\mathrm{O}$ documento destaca que o acentuado incremento nas importaçóes originárias do Brasil não se verificou, nem houve mudança significativa na penetraçáo de produtos brasileiros em segmentos do mercado argentino em que havia grande participação dos importados. No setor de material de transporte, por exemplo, a participaçáo dos importados brasileiros dentro do total de importações argentinas do setor caiu de $38 \%$ no período de 
1997 a 1998 para $31,3 \%$ em 1999 e de $18,4 \%$ para $17,3 \%$ no segmento de produtos químicos, em igual período comparativo. Outros setores mostraram incrementos discretos ou se mantiveram praticamente estáveis.

Este comportamiento estaría sustentando la hipótesis acerca de que el efecto-ingreso tiene un peso mayor que el efecto-precio como generador de comercio entre la Argentina y Brasil. Siguiendo este concepto, la recesión experimentada por la Argentina y el estancamiento de la economía de Brasil predominaron sobre el cambio de precios relativos que a partir de la devaluación se dio a favor de los productos brasileńos, induciendo la retracción en el intercambio entre ambos socios comerciales (COMISSÃO NACIONAL DE COMÉRCIO EXTERIOR, 1999, p. 91).

Outro temor que não se concretizou em 1999 foi o de migração em massa das empresas argentinas para o Brasil, em busca de menores custos de produção. Em seu Boletim Mercosul no 70, intitulado "El traslado de empresas argentinas a Brasil" e publicado em 6 de novembro de 2000, a Fundação BankBoston da Argentina lembra que no final de 1999 se criou "uma psicose" nos meios de comunicação sobre a possível migração de empresas argentinas.

Tal psicose ganhou força particularmente após ter chegado à imprensa um relatório reservado (que não foi oficialmente publicado) elaborado pela União Industrial Argentina, entidade semelhante à Confederação Nacional da Indústria (CNI) do Brasil. Neste documento, a agremiação industrial afirmava que mais de 100 empresas instaladas na Argentina haviam transferido sua produção total ou parcialmente para o Brasil nos últimos 12 meses, sendo que, deste total, 70 companhias seriam de grande e médio porte.

Pero lo cierto es que más allá de un puñado de compañías del sector automotor y algún caso puntual, el temido éxodo masivo no se produjo. En realidad, en la mayor parte de los casos lo que se dio fue un proceso de traslado parcial de líneas de producción a Brasil manteniendo otras en el país. Este movimiento es lógico que ocurra en la medida en que se va intensificando el proceso de integración del MERCOSUR. En la práctica 
muchas empresas brasileñas han instalado plantas productivas en la Argentina sin que eso signifique que decidieron abandonar la producción en su propio país (FUNDAÇÃO BANKBOSTON, 2000, p. 1).

Entre as explicações para que o temido êxodo não tivesse ocorrido, o relatório lembra que muitas empresas, especialmente as pequenas, descobriram que os custos da transferência para o Brasil estavam aquém de sua capacidade financeira.

O levantamento da Fundação BankBoston aponta algumas empresas que efetivamente transferiram sua produção para o Brasil. Entre elas a Goodyear, que em novembro de 1999 centralizou no Brasil suas atividades para o Mercosul. Fate, Firestone e Pirelli também trasladaram parte de sua produção para o Brasil.

As análises pós-1999 não deixam dúvidas de que grande parte do temor naquele ano não tinha qualquer fundamento, ou seja, nem as empresas se transferiram em massa para o Brasil, nem os produtos brasileiros inundaram a Argentina. No calor da crise, no entanto, tal realidade não se apresentava táo clara e os receios de empresários e políticos alimentaram as disputas setoriais.

Em grande parte, os governos de Brasil e Argentina reagiram mais com ameaças recíprocas do que com atos concretos para restringir o comércio bilateral. Entretanto, medidas como salvaguardas temporárias, restriçóes técnicas e sanitárias, entre outras, foram suficientes para prejudicar o comércio, mesmo que temporariamente, seja pelo aumento da burocracia, pelo estabelecimento de cotas, pela suspensão em si das compras ou simplesmente pelo travamento de negociaçóes importantes, como a do novo modelo do setor automobilístico.

A primeira reunião entre os presidentes Fernando Henrique Cardoso (Brasil) e Carlos Menem (Argentina) para discutir os efeitos da desvalorização da moeda brasileira sobre o comércio da região ocorreu em 12 de fevereiro, em São José dos Campos (SP). Naquela ocasião, o governo argentino encontrava-se encurralado pelas demandas do seu setor industrial por medidas de proteção para impedir uma avalanche de produtos brasileiros. Um dos objetivos da reunião era justamente apaziguar a tensão entre os dois países, que vinha se acentuando. 
Entre as poucas medidas concretas resultantes desse encontro, estava a decisão do governo brasileiro de redirecionar os recursos do Programa de Financiamento às Exportaçóes (PROEX) para as vendas destinadas a mercados mais competitivos, como Estados Unidos e União Européia. Nas vendas ao Mercosul, os recursos ficaram limitados às exportaçóes de máquinas e equipamentos (bens de capital). Outra medida importante foi a redução para 24 horas no prazo para a concessão das licenças de importação de produtos do Mercosul, que até então levavam cerca de 72 horas. Por sua vez, Menem se comprometeu a não aplicar qualquer medida protecionista unilateral.

\section{Evidências para alguns setores selecionados}

A discussão anterior torna-se mais interessante quando são consideradas questóes setoriais específicas. A seguir, uma breve análise dos conflitos que envolveram os setores automotivo, têxtil, siderúrgico e de frango durante o tumultuado ano de 1999.

\section{Setor automotivo}

Um dos principais alvos de disputa durante a crise. Afinal, o Brasil era o principal destino das exportações automobilísticas argentinas. Além disso, em 1999 deveria ser definido um novo regime de comercialização dentro do bloco.

Segundo o Anuário de 1999 da Associação das Fábricas de Automotores da Argentina (ADEFA), a produção de veículos do país caiu para 304.809 unidades naquele ano, interrompendo uma trajetória de crescimento que vinha desde 1995, com produçáo de 285.435 unidades, atingindo as 457.957 unidades em 1998. As exportações argentinas de automóveis completos caíram de 237.497 em 1998 para 98.362 unidades, o que representou um declínio em valor FOB (Free on board - não incluem os custos com seguros e fretes) de US\$ 2,539 bilhôes para US\$ 1,053 bilhão no período. No total (automóveis e autopeças), as exportaçóes argentinas recuaram de US\$2,918 bilhões em 1998 para US\$1,581 bilhões em 1999.

Os números não deixam dúvidas de que a crise foi um duro golpe para a indústria argentina. Entretanto, mais do que a corrente de comércio entre os 
dois países no setor, o que realmente preocupava o governo argentino era a possibilidade das montadoras se transferirem para o Brasil.

A Fiat, por exemplo, anunciou que a partir de março começaria a fabricar temporariamente em Betim o modelo Siena, até então importado da Argentina, aproveitando que os custos brasileiros haviam se tornando menores. A empresa italiana não chegou a fechar sua fábrica de Siena em Córdoba, mas a produção foi reduzida e passou a atender apenas ao mercado argentino. Já a Mercedes-Benz anunciou a intenção de substituir fornecedores argentinos por brasileiros. A fabricante de autopeças francesa Valeo comunicou que até o final do primeiro semestre de 1999 pretendia fabricar no Brasil os componentes que servissem para ambos os países, até então produzidos na Argentina. As fábricas argentinas continuariam funcionando, mas produzindo apenas para empresas lá instaladas.

Tais notícias levaram os produtores argentinos a pressionarem o governo por uma prorrogação do regime automotivo até 2004. Pelo cronograma inicial acordado pelos governos dos dois países em 1998, a partir de janeiro de 2000 entraria em vigor um novo regime automotivo dentro do bloco, com liberalização total do comércio intrazona, suspensão de quaisquer incentivos fiscais e Tarifa Externa Comum de 35\% para a importação de automóveis de terceiros países.

A Associaçáo Nacional dos Fabricantes de Veículos Automotores (ANFAVEA) era favorável a um regime de transição, mas somente até 2003, enquanto o governo brasileiro se dizia contra qualquer adiamento.

Além de compensações pela desvalorização cambial brasileira, os produtores argentinos pediam o fim dos subsídios dados pelo governo brasileiro à instalação de montadoras estrangeiras no país. Em julho de 1999, o governo argentino protestou oficialmente ao Ministério das Relaçóes Exteriores do Brasil contra os subsídios e benefícios que o país concederia à fábrica da Ford na Bahia.

A Medida Provisória 1.562, de dezembro de 1996, dava incentivos fiscais às empresas que se instalassem no Norte, Nordeste e Centro-Oeste do Brasil, como redução de até 50\% no Imposto de Renda, de 90\% nas importações de matérias-primas e insumos e isenção de tributos como o Imposto sobre Produtos Industrializados (IPI), entre outros benefícios. 
Tais incentivos valeriam, entretanto, apenas até 31 de março de 1997. Para permitir os benefícios fiscais à fábrica da Ford, o Congresso brasileiro aprovou o que ficou conhecida como a "Emenda Ford", que estendia os incentivos tributários até o final de 1999. O governo vetou parcialmente a emenda, mas posteriormente emitiu decreto que garantia os incentivos à Ford e os estendia a outras empresas automotores que desejassem se instalar no Nordeste, Norte ou Centro-Oeste do país, o que não agradou aos seus sócios do Mercosul. Graças às pressóes do governo argentino, o Brasil desistiu de estender o prazo da Medida até 2010. Pelo acordado no âmbito do Mercosul, se algum dos países-membro desejasse outorgar benefícios a uma empresa a partir de $1^{\circ}$ de janeiro de 2000 , seria necessária permissão dos demais membros. Estava assim superada a disputa com o governo federal, mas restavam ainda os incentivos fiscais dados pelos governos estaduais, via redução ou isenção de ICMS.

No setor de autopeças argentino, uma das demandas era a exigência de que o novo acordo automotivo impusesse um conteúdo nacional de autopeças de no mínimo 50\% nos veículos produzidos no país. E tanto o setor de autopeças como o de automóveis defendiam que a tarifa zero nas importaçóes intrabloco só fosse aplicada para as montadoras que possuíssem investimentos tanto no Brasil como na Argentina.

No início de junho, a Associação de Fábricas de Automotores da Argentina e a Associação Nacional de Fabricantes de Veículos Automotores chegaram a um acordo preliminar em Buenos Aires sobre como deveria funcionar o período de transição entre $1^{\circ}$ de janeiro 2000 e 31 de dezembro de 2003, antes da entrada em vigor do livre comércio dentro do bloco. Pelo acordo, entraria em ação um sistema de compensação no comércio intrabloco em dólares e tarifa de 35\% para os veículos importados de terceiros países. Ficou definido ainda que qualquer regime de promoção de negócios do setor deveria valer para todos os países do Mercosul. Esse último item veio resolver a disputa em torno do Plano de Troca (Plan Canje, lançado em março na Argentina e que oferecia descontos para quem trocasse o carro usado por um novo), que não previa os mesmos incentivos para os automóveis produzidos em outros países do bloco. 
No início de agosto, as duas entidades acordaram ainda a existência de um conteúdo local dentro do conteúdo regional mínimo de $60 \%$, estabelecido anteriormente. Além disso, os empresários brasileiros aceitaram que a Argentina contasse com um prazo maior para aumentar as tarifas alfandegárias das autopeças compradas de fora do Mercosul.

Enquanto os empresários do setor tentavam fechar um acordo, os deputados argentinos aprovaram no início de agosto um projeto de lei que estabelecia que os veículos de produção nacional teriam um índice mínimo de 50\% de componentes nacionais (como porcentagem do conteúdo regional). $\mathrm{O}$ projeto também propunha criar um "comércio equilibrado", determinando que não poderia haver mais de dois trimestres com saldo negativo entre as exportaçóes de uma empresa e suas importaçóes. Mais do que aprovar e executar tal projeto de lei, a idéia dos deputados argentinos era a de utilizar a ameaça de aprovação como elemento negociador, pressionando o governo brasileiro a adotar medidas de compensação no comércio bilateral.

Na prática, no entanto, a medida servia apenas para dificultar as negociaçóes setoriais, em meio à desconfiança de que uma decisão governamental poderia simplesmente invalidar o que havia sido acordado e deixar um dos lados com o ônus de oferecer vantagens sem receber contrapartidas.

As negociaçóes setoriais desandaram ao longo do segundo semestre em relação às regras do regime transitório. No início de dezembro, o próprio Fernando Henrique Cardoso já admitia publicamente que o acordo automotivo entre os dois países poderia ser prorrogado por mais alguns meses, caso não fosse possível chegar a um acordo até o dia 31. A prorrogação, entretanto, esbarrava nas regras da OMC, que previam o fim dos regimes regionais e nacionais até o final de 1999.

No final de dezembro, os dois países fecharam um acordo transitório para o setor automotivo, com validade de sessenta dias, sendo posteriormente estendido até junho. Logo no início do ano, entretanto, a Argentina resolveu entrar com um pedido formal na OMC de prorrogação por mais sete anos de seu programa interno de incentivos ao setor, descumprindo assim o acordado com o Brasil (extinção dos regimes de incentivo nacionais até o dia 31 de dezembro de 1999). Na ocasião, o Brasil ameaçou cobrar tarifa de 35\% dos automóveis argentinos. Em meados de março, os governos dos dois países 
chegaram a anunciar o fechamento de um acordo no setor automotivo. Entretanto, o setor seguiu com disputas e renegociaçóes nos anos seguintes.

\section{Setor têxtil}

Responsável pela maior disputa técnica e institucional dentro do Mercosul em 1999, com a Argentina aplicando salvaguarda e o Brasil recorrendo à Organização Mundial de Comércio.

Para entender a disputa, no entanto, não se pode esquecer que, desde a criação do bloco, o setor têxtil foi considerado sensível pela Argentina. Graças às negociações mantidas com o Brasil em 1994, o governo argentino conseguiu que os produtos têxteis constituíssem uma exceção dentro do Programa de Liberalização Comercial do bloco (1991-1994), que objetivava a criação de uma zona de livre comércio (tarifa zero). Com isso, a Argentina ganhava o direito de rebaixar de forma mais gradual as tarifas nacionais para tais produtos no comércio dentro do bloco, chegando a zero no final de 1998.

Já em outubro de 1998, a Federação de Indústrias Têxteis Argentinas entrou com pedido de investigação junto à Comissão Nacional de Comércio Exterior. Em fevereiro de 1999, o juiz federal Ricardo Maturana, da província de Tucumán, emitiu uma resolução cautelar, dirigida ao Ministério da Economia, de proteção para a indústria têxtil local, com o objetivo de frear as importaçóes de roupas e calçados do Brasil.

Em 16 de julho de 1999, o Ministério da Economia da Argentina publicou no Diário Oficial a Resolução do Ministério da Economia e Obras e Serviços Públicos no 861/99, estabelecendo uma medida de salvaguarda, com base no artigo $6^{\circ}$ do Acordo de Têxteis e Vestuário da OMC. Pela medida, as exportações do Brasil, China e Paquistão de tecidos de algodão e suas mesclas ficavam, a partir de 31 de julho de 1999 e por um período de trinta e seis meses, sujeitas a cotas anuais. Foi a primeira salvaguarda adotada dentro do bloco.

O governo brasileiro reagiu, alegando que a medida não encontrava respaldo no marco jurídico do Mercosul e recorreu da decisão argentina tanto no Tribunal Arbitral do Mercosul como na OMC.

$\mathrm{Na}$ verdade, o governo argentino já havia regulamentado no final de 
junho o sistema de salvaguardas previsto na resolução de no 70 da Associação Latino-Americana de Integração (ALADI), abrindo assim a porta para adoção de medidas restritivas no comércio intrabloco. A decisão argentina fundamentava-se no Tratado de Assunção de 1991, que havia criado uma cláusula de salvaguarda dentro do Mercosul, permitindo a aplicação de cotas por produtos toda vez que houvesse aumentos bruscos e fortes nas importações originárias de algum dos países sócios.

Entretanto, o mecanismo só poderia ser acionado se ficasse provado que esse incremento brusco nas importaçóes estava relacionado ao programa de liberalização comercial do bloco e tinha data certa para ser extinto: 31 de dezembro de 1994. Por este mecanismo, que tinha validade de um ano prorrogável por mais um, as cotas determinariam o quanto do produto em questão poderia entrar no país que se considerava prejudicado utilizando as tarifas preferenciais. $\mathrm{O}$ que excedesse a cota receberia tributação igual a de países não-pertencentes ao bloco.

Os funcionários argentinos alegavam que o programa de liberalização do bloco previa uma harmonização das políticas macroeconômicas dos países-sócios, o que não havia ocorrido até 1999, tornando, portanto, legítimo o pleito por salvaguardas. Além disso, como o Mercosul não havia regulamentado qualquer mecanismo de compensação em caso de mudanças macroeconômicas bruscas, os funcionários argentinos defendiam a utilização das determinações da ALADI, suprindo assim a ausência de um marco legal do Mercosul.

Em 23 de julho de 1999, o subsecretário do comércio exterior do Ministério da Economia da Argentina, Felix Peña, publicou artigo na Gazeta Mercantil intitulado "As salvaguardas argentinas". No texto, ele lembra que o Mercosul se insere num marco mais amplo de compromissos que incluem a ALADI e a OMC.

Em várias conversaçóes mantidas foi aceito o argumento de que a medida não deveria ser aplicada ao Brasil porque isso não é permitido pela norma vigente. Examinou-se a fundo a argumentação apresentada, e não se encontrou base legal sólida que permitisse negar o direito invocado por uma parte interessada que reclamava a aplicação das salvaguardas. 
Nenhuma norma do Mercosul exclui a possibilidade da aplicação desse tipo de salvaguarda. Há, na matéria, um claro vazio legislativo. Nenhuma iniciativa dos sócios tentou preenchê-lo (PEÑA, 1999, p. A2).

Peña destaca que a única norma vigente sobre esse tópico seria o regulamento relativo à aplicação de salvaguardas às importações provenientes de países não-membros do Mercosul, aprovado pela Decisão CMC 17/96. Por esse regulamento, ficavam excluídas importações originárias do Mercosul quando um sócio aplica salvaguardas a importaçóes provenientes de outros países, mas o subsecretário destaca que tal regulamento náo se aplica às salvaguardas da OMC.

A Argentina cumpriu essa norma ao excluir as importaçóes do Brasil das salvaguardas aplicadas em 1997 aos calçados. Essa exceção não foi compreendida em toda a sua dimensão jurídica pelo recente parecer do panel sobre calçados da OMC, que a considera, incorretamente, uma violação do Acordo de Salvaguardas. Essa exceção explica que havia ocorrido um aumento muito vigoroso de importaçóes de calçados originários do Brasil, fato significativamente acentuado em 1999, depois da desvalorizaçáo do real, gerando um problema ainda não-resolvido no comércio bilateral.

A Resolução Ministerial no 861 ajusta-se ao ATV e à legislação vigente. Não viola nenhum compromisso da Argentina no Mercosul. Não existem argumentos jurídicos válidos para excluir o Brasil de uma medida prevista em um compromisso internacional que é lei da naçáo. Outra resolução ministerial aplica uma medida parecida ao Paquistão, também membro da OMC. Aplicar a medida ao Paquistão e não ao Brasil poderia ser considerado pela OMC uma discriminação, sem que esta pudesse invocar uma norma do Mercosul, como foi possível fazer, em circunstâncias legais diferentes, no caso das salvaguardas dos calçados (PEÑA, 1999, p. A2).

A resposta a Félix Peña veio no mesmo jornal, em 29 de julho, em artigo 
intitulado "Salvaguardas argentinas, outra visão", assinado por Fernando P. de Mello Barreto, então assessor especial do Ministério do Desenvolvimento, da Indústria e do Comércio do Brasil.

Afirma Félix Peña que 'nenhuma norma do Mercosul exclui a possibilidade da aplicação desse tipo de salvaguarda'. A afirmação surpreende, pois o Tratado de Assunção, ato constitutivo do Mercosul, dispóe expressamente, no seu Anexo IV, artigos 1 e 5, que os Estados-partes poderiam aplicar salvaguarda somente até 31 de dezembro de 1994. A partir de entáo encontra-se claramente vedado esse tipo de medida entre os Estados-partes da união aduaneira. Nem poderia ser outra a intenção dos signatários do Tratado, pois a imposição de restrições entre sócios constituiria uma contradição: de um lado eliminar tarifas e, de outro, impor medidas não-tarifárias ao comércio intrazona (BARRETO, 1999, p. A2).

Sobre a decisão CMC 17/96, Barreto destaca:

Trata-se de norma que aprovou o regulamento do Mercosul para salvaguardas às importaçóes provenientes de países náo-membros do Mercosul. Em suas disposições transitórias, o regulamento determina (artigo 98) que 'quando forem aplicadas medidas de salvaguarda... excluir-se-ão das mesmas as importaçóes originárias dos Estados-partes'. O dispositivo reitera, portanto, o princípio do Tratado de Assunção, que proíbe salvaguardas entre os Estados-membros da união alfandegária (BARRETO, 1999, p. A2).

O assessor também comenta a exclusão do Brasil da aplicação das salvaguardas argentinas no setor de calçados, em 1997, que, segundo Pena (1999), teria sido considerada ilegal pela OMC.

Examinemos os fatos e a decisão do panel da OMC. Para provar o dano à indústria argentina, seu governo incluiu no cálculo das importaçóes do produto aquelas feitas aos países-membros do Mercosul. A medida, no entanto, dirigiu-se a países não-membros do Mercosul, os quais - não sem 
razão - argüiram não poder ser objeto de salvaguardas que tinham origem em importaçóes pelas quais não respondiam integralmente. Tratou o panel de proibir a regra do Mercosul, que determina a exclusão dos sócios da aplicação de salvaguardas? Claramente não. Nem poderia fazê-lo, pois a exclusão encontra respaldo no artigo XXIV do Gatt. Em sua linha de argumentos, o autor do artigo sob exame expressa entendimento de que aplicar as salvaguardas a importaçóes de têxteis do Paquistão e não do Brasil poderia ser considerada, pela $\mathrm{OMC}$, uma discriminação. $\mathrm{O}$ artigo XXIV do Gatt existe exatamente para permitir exceçôes à cláusula da nação mais favorecida no caso do comércio entre membros de áreas de livre comércio e unióes aduaneiras (BARRETO, 1999, p. A2).

Barreto lembra ainda que toda a argumentação do subsecretário argentino para demonstrar a excepcionalidade da questão dos têxteis esbarra na decisão argentina de recorrer à resolução no 70 da ALADI.

Ainda que 'ad argumentandum' se admitisse a alegação da excepcionalidade para têxteis, como se justificaria, então, a aplicaçáo de salvaguardas a outros produtos à luz do Tratado de Assunção de 1991 (que, aliás, tornou superado, no âmbito do Mercosul, o ato da ALADI de 1987)? (BARRETO, 1999, p. A2).

Em fevereiro de 2000, o Brasil pediu a abertura de um panel na OMC contra a Argentina, alegando que o país desrespeitava as regras do comércio internacional ao estabelecer barreiras aos produtos têxteis brasileiros. A Argentina já havia ignorado a recomendação do Órgão de Monitoramento de Têxteis da OMC, que em outubro considerou ilegais as salvaguardas impostas pelo vizinho sul-americano. O parecer do Órgão, no entanto, tinha caráter apenas recomendativo e não obrigatório.

Em março de 2000, o Tribunal Arbitral do Mercosul considerou por unanimidade improcedente a salvaguarda, obrigando o governo argentino a suspender a medida.

De acordo com o laudo arbitral, os artigos 1 e 5 do Anexo IV do Tratado de Assunção formulam uma proibição geral sobre a aplicação de salvaguardas dentro do bloco, que somente poderá ser executada por meio de uma 
norma específica que legitime a imposição de tais medidas. E os árbitros do Tribunal disseram não ter encontrado normas do Mercosul que permitissem a aplicação de salvaguardas à importação de produtos têxteis intrazona. Com isso, o Tribunal pôs fim às discussóes sobre o suposto "vácuo legal" no que se refere à utilização de salvaguardas dentro do bloco.

Logo após a decisão do Tribunal Arbitral, foi a vez da OMC acatar o pedido de abertura de panel contra a Argentina, dificultando ainda mais a manutenção da posição argentina.

As desavenças no setor têxtil foram responsáveis pelo mais grave momento da crise vivida pelo Mercosul em 1999, quando o governo brasileiro decidiu suspender, em 26 de julho, todas as negociações no âmbito do Mercosul, logo após a publicação no Diário Oficial argentino da resolução que permitia e regulava a adoçáo de salvaguardas contra produtos originários de qualquer país da ALADI, incluindo os do Mercosul. O Itamaraty subiu o tom das críticas à Argentina, com o chanceler Luiz Felipe Lampreia classificando em várias ocasióes de inaceitáveis e de "grave precedente" as medidas argentinas. O recém empossado ministro do Desenvolvimento, Indústria e Comércio, Clóvis Carvalho, também divulgou nota afirmando que salvaguardas, alegaçóes de dumping e exigências de certificaçóes abusivas não seriam toleradas de forma alguma pelo governo brasileiro.

O governo brasileiro enviou ainda um pedido ao Uruguai, que ocupava a presidência do bloco, para convocação de uma reunião extraordinária do Grupo Mercado Comum, com o objetivo de encontrar uma saída para a crise.

No auge da crise, Carlos Menem chegou a anunciar o cancelamento de uma visita que faria ao Brasil em início de agosto. O próprio Fernando Henrique Cardoso criticou em público a decisão da Argentina de procurar respaldo nas regras da ALADI para aplicar salvaguardas contra produtos produzidos no bloco. "Nós temos confiança de que a Argentina compreenderá que há regras que não podem ser ultrapassadas", afirmou FHC, lembrando que o Tratado de Assunção redefiniu as regras no âmbito da ALADI. (SOARES, CHADE, 1999, p. A6).

As pressóes surtiram efeito e em 29 de julho o governo argentino aceitou revogar a resolução 911 do Ministério da Economia, que permitia as 
salvaguardas para os produtos originários do Mercosul. A concessão foi feita após o governo brasileiro ter estabelecido a revogação como condição para receber Menem e assim retomar as negociaçóes dentro do Mercosul.

A análise dos dados anuais mostra que as exportaçóes brasileiras para a Argentina no setor têxtil declinaram em 1999 para US\$270,3 milhóes, ante os US\$ 299,1 milhóes de 1998, segundo dados da SECEX e da Fundação Centro de Estudos do Comércio Exterior (FUNCEX). Na verdade, este foi o primeiro ano de queda desde 1990, trajetória que iria se manter até 2002, tendo apenas o ano de 2000 como exceção. Os dados trimestrais, no entanto, ajudam a entender o temor dos argentinos. Do terceiro trimestre de 1998 até os três primeiros meses de 1999, as vendas brasileiras do setor têxtil para a Argentina vinham em trajetória decrescente, passando de US\$ 91,45 mil para US\$ 56,88 mil no período. A partir de então, entretanto, as vendas voltaram a ganhar fôlego, chegando a US\$ 66,04 mil no segundo trimestre, US\$ 69,35 mil no terceiro e a US\$ 78,01 mil nos últimos três meses do ano. Crescimento este que só não foi maior, em grande parte, devido às medidas restritivas adotadas pela Argentina.

\section{Siderúrgico}

O ano de 1999 começa com o parecer favorável da Comissão Nacional de Comércio, em fevereiro, à adoção de sobretaxas entre $9,44 \%$ e 51,05\% às importaçóes de laminados a quente oriundos do Brasil.

O setor siderúrgico brasileiro, no entanto, apontava irregularidades no processo de antidumping, alegando que foram levados em conta apenas os dados da empresa argentina SIDERAR, que havia pedido a abertura do processo, não utilizando os números apresentados pelos produtores brasileiros, consultados uma única vez durante todo o processo.

Outros erros apontados pelos produtores brasileiros: a Comissão não definiu, por ocasião da instauração do processo, o período da ocorrência de dumping, tendo posteriormente definido-o entre o segundo semestre de 1997 e o primeiro de 1998. Mesmo assim, a Comissão utilizou a desvalorização do real para justificar a maior competitividade do produto brasileiro. ${ }^{4}$

Além disso, a CNCE não teria conseguido comprovar danos à indústria

${ }^{4}$ Para mais informações ver Ferrari (1999, p. A5). 
local e sim apenas "indícios de ameaças de danos" que "poderiam acentuarse durante o período restante da investigação". Por fim, o setor siderúrgico brasileiro acusava a SIDERAR de falsificação das acusaçóes, já que incluíam produtos que nem eram fabricados na Argentina. Os empresários brasileiros alegavam ainda que o laminado brasileiro chegava ao mercado argentino com preço superior ao praticado em outros mercados.

Ainda assim, em abril o Ministério da Economia aceitou a denúncia de dumping, permitindo a imposição de tarifas que compensassem a diferença de preços entre o valor de exportação e o praticado nos mercados de origem.

Pela resolução 458, o governo fixou por quatro meses um valor mínimo de exportação FOB de US\$ 410 a tonelada para os produtos brasileiros, valor acima inclusive dos US\$315 estabelecidos para os produtos originários da Rússia e da Ucrânia, cujos produtores também foram acusados de dumping.

Em julho de 1999, o setor siderúrgico brasileiro sofreu novo revés, após a Comissão Nacional de Comércio Exterior da Argentina ter aceitado um novo pedido de investigação antidumping apresentado pela SIDERAR, desta vez contra os laminados a frio importados do Brasil e da Rússia, alegando que tais produtos contavam com subsídios ilegais.

Para exasperar ainda mais as relaçóes bilaterais, a Gerdau e a Companhia Siderúrgica Belgo-Mineira ameaçaram no final de agosto apresentar uma denúncia de dumping contra as importaçóes da Argentina. A ação visaria os vergalhóes argentinos e teria como alvo a argentina Acindar.

Em setembro, o documento no 548 apresentou a conclusão definitiva da Comissão sobre os laminados a quente, confirmando a ameaça de "dano importante" apontada na decisão preliminar de fevereiro.

Em dezembro, o governo argentino publicou resolução acatando a proposta apresentada pelos representantes do setor siderúrgico brasileiro em outubro, estabelecendo preços mínimos válidos por cinco anos, suspendendo assim os direitos de antidumping.

Além das acusações de dumping, os empresários brasileiros também enfrentaram barreiras não-tarifárias no setor siderúrgico. No final de junho, a Argentina passou a exigir o pagamento de um depósito caução para liberar na alfândega os tubos de aço importados do Brasil. O depósito cobrado equivalia ao pagamento em dinheiro de $6 \%$ do valor da mercadoria 
importada. Coincidentemente, esse era o mesmo percentual cobrado na alíquota do imposto de importação sobre as importaçóes de tubos de aço que entravam na Argentina no ano anterior.

Desde janeiro de 1999, as tarifas dentro do bloco para o aço caíram para zero, devido ao fim do regime de adequação dentro do Mercosul. Além disso, os tubos de aço, assim como os produtos elétricos de baixa tensão, precisavam ainda cumprir a resolução no 409 , que exigia certificação técnica por empresa Argentina.

\section{Frango}

Em 31 de março chegou ao fim o regime de cotas de exportação, firmado em outubro de 1998, que limitava as vendas do Brasil à Argentina. O acordo tinha como contrapartida a extinção do processo de antidumping contra o Brasil, o que não foi cumprido, já que em meados de janeiro a Comissão Nacional de Comércio Exterior da Argentina considerou procedente o pedido de abertura de investigação sobre a existência de dumping nas operações de importação de frango originárias do Brasil (Resolução 11/99).

O fim do acordo aliado à desvalorização do real potencializou os temores dos produtores argentinos, que pediam ao governo de seu país que limitasse a entrada de produtos brasileiros.

Em junho de 1999, o processo no 531 sobre a investigação preliminar de dumping em relação a "frangos inteiros sem vísceras, com ou sem miúdos comestíveis colocados no interior da cavidade abdominal, fresco ou refrigerado e congelado" da Comissão Nacional de Comércio Exterior da Argentina não encontrou indícios de dano à indústria nacional causado pelas importaçóes brasileiras. Dessa forma, a Comissão considerou conveniente não aplicar medidas provisórias de sanção até que a investigação estivesse concluída.

Diante da resposta negativa, o Centro de Empresas Processadoras Avícolas (CEPA) entrou com pedido na justiça de restrição de importação do frango brasileiro, alegando iminente risco de desaparecimento da atividade de avicultura na Argentina devido à concorrência do produto brasileiro. Em novembro de 1999, o juiz Juan José Papetti da corte federal da cidade de Concepción del Uruguay (província de Entre Ríos) determinou a aplicação 
imediata de medidas de restrição às importaçóes de frango do Brasil, estabelecendo uma cota mensal até que a Subsecretaria de Comércio Exterior avaliasse a validade da acusação de dumping feita pelas empresas avícolas argentinas.

O governo brasileiro ameaçou aplicar impedimentos às importaçóes de leite em pó originário da Argentina, como medida de retaliação. O Ministério da Economia argentino entrou com recurso contra a medida no Tribunal de Apelações, que lhe deu parecer favorável. Entretanto, um novo recurso extraordinário foi apresentado e aceito na Câmara Federal.

Em dezembro de 1999, a Comissão Nacional de Comércio Exterior da Argentina concluiu via o ato administrativo no 576 que os produtores locais de frango para consumo direto sofriam "dano importante" devido às importaçóes originárias do Brasil, abrindo espaço para que a Subsecretaria de Comércio Exterior aplicasse no início de 2001 a imposição de direitos adicionais ao comércio dentro do bloco.

Em janeiro de 2000, a Uniāo Brasileira de Avicultura chegou a cogitar a abertura de uma ação judicial de perdas e danos contra a decisão argentina de estabelecer cotas para as exportaçóes brasileiras. A ameaça não se concretizou, entretanto, já que o governo argentino conseguiu suspender a medida.

No início de março, contudo, as exportações brasileiras de frango voltaram a ser limitadas por cotas, devido à determinação da Câmara Federal de Apelação da Província de Entre Ríos.

Durante o ano de 1999, os produtores do setor de avicultura do Brasil também reclamaram da exigência feita pelo governo argentino de obrigatoriedade de exames laboratoriais fitossanitários e de um certificado de origem adicional. Em matéria publicada pela Gazeta Mercantil no dia 12 de maio, Zoé Silveira d'Ávila, presidente da União Brasileira de Avicultura, apontava despesas de US\$ 1.160 por tonelada com a análise de amostras da carne de frango brasileira, apesar de existir um serviço laboratorial gratuito no Brasil, aceito no restante do mundo. Cada certificado teria custo de US\$20 e terminava retendo os caminhóes frigoríficos na fronteira. Segundo a matéria, o serviço foi terceirizado na Argentina, sendo operado por multinacionais como a suíça SGS e pago pelos exportadores. O texto chama ainda atenção para o fato de que, durante o encontro de São José dos Campos em fevereiro, 
os presidentes Fernando Henrique Cardoso e Carlos Menem terem acordado a consolidação de um Sistema Origem-Destino, que previa equivalência dos sistemas de inspeção no Mercosul. Dessa forma, os estabelecimentos de origem ficariam responsáveis pela emissão dos certificados de inspeção e teriam livre trânsito nas aduanas.

\section{Conclusão}

A crise de 1999 certamente ensinou que um ajuste brusco no câmbio bilateral não é suficiente, por si só, para que um país seja invadido pelas exportações de seus principais parceiros comerciais. A desvalorização, no entanto, tem o poder de dar outro fôlego a antigas demandas protecionistas setoriais, fortalecendo lobbies e dificultando as negociações entre os governos.

Isso pode ser claramente observado nas disputas de 1999. No campo siderúrgico, a CNCE usou a desvalorização como justificativa para uma acusação de dumping, apesar do período analisado ser anterior a este episódio (segundo semestre de 1997 e o primeiro de 1998). No setor têxtil, cansada de esperar a regulamentação de mecanismos de compensação dentro do bloco e diante da pressão de produtores que temiam uma invasão de produtos brasileiros, a Argentina optou por unilateralmente aplicar salvaguardas dentro do Mercosul, com base nas normas existentes dentro da ALADI.

A falta de uma clara e efetiva institucionalização do Mercosul talvez tenha sido a principal lição deixada pela crise de 1999. Faltou naquele período, e ainda hoje, a presença de organismos supranacionais que pudessem ter exercido o papel de mediadores. Como tais organismos não existiam, o que se viu foi uma guerra de acusaçóes trocadas entre empresários e, pior, entre representantes dos dois governos nas páginas dos principais jornais dos dois países, atrapalhando as poucas negociaçóes que conseguiam ir adiante.

Durante a crise, a ameaça, mais do que a negociaçáo, foi a principal moeda de troca para aparar as arrestas. Ambos os governos se utilizaram de licenças não-automáticas, exigências sanitárias ou de regulamentação como mecanismos de pressão. Foi suspendendo todas as negociaçóes dentro do bloco, por exemplo, que Fernando Henrique Cardoso fez com que Carlos Menem voltasse atrás na questão das salvaguardas. Foi também com a 
ameaça de reduzir as tarifas de importação de veículos oriundos de terceiros países que a Argentina conseguiu que o governo brasileiro aceitasse discutir a prorrogação do regime de transição para o setor automotivo.

Mas a crise também teve seu lado positivo. Um deles foi a disposição dos empresários buscarem acordos que mantivessem em funcionamento os canais montados dentro do Mercosul, apesar da crise. Além disso, o Tribunal Arbitral desempenhou papel fundamental, dando pareceres importantes na questão têxtil, por exemplo, quando não deixou dúvidas sobre a ilegalidade da aplicação das salvaguardas, comprovando que a estrutura jurídica do Mercosul era suficientemente clara quanto à impossibilidade de utilização desse tipo de instrumento.

O Mercosul sobreviveu à crise de 1999, mas continua alternando períodos de lentos avanços ou de estagnação, com outros de "relançamento" do bloco. Para avançar como bloco, é imprescindível a criação de organismos supranacionais que comandem as negociaçóes, determinando calendários, cumprindo os prazos, não deixando que a integração fique subordinada à simpatia ou náo de determinado chefe de governo com relação ao Mercosul.

Além disso, não se pode perder de vista que o bloco reúne países em desenvolvimento, e que, apesar dos avanços macroeconômicos dos últimos anos, são mais suscetíveis à crises. Sendo assim, se realmente não quiser se limitar a uma mera área de livre comércio, é fundamental que o Mercosul leve adiante a coordenação das políticas macroeconômicas que, aliada à institucionalização do bloco, reduziria o poder dos lobbies protecionistas. Talvez o sonhado projeto de uma moeda única seja uma utopia. Mas o Mercosul é um fato. Resta saber o que seus países-membro realmente querem dele. 


\section{Referências Bibliográficas}

ALMEIDA, H.; RIGGI, H. Surpresa e preocupação nos mercados da Argentina. Gazeta Mercantil, São Paulo, p. B8, 14 jan. 1999.

ASSOCIAÇÃO DE FÁBRICAS DE AUTOMOTORES DE ARGENTINA (ADEFA) Anuário 1999. Buenos Aires, 1999. Disponível em: http://www. adefa.com.ar/informacion_estadistica/index.html. Acesso em: 05 set. 2005.

BARRETO, Fernando P. de Mello. Salvaguardas argentinas, uma outra visão. Gazeta Mercantil, São Paulo, p. A2, 29 jul. 1999.

BEVILAQUA, Afonso. Macroeconomic coordination and commercial integration in Mercosur. Rio de Janeiro: Departamento de Economia da Pontifícia Universidade Católica do Rio de Janeiro PUC-Rio, n. 378, 1997. (Texto para Discussão).

COMISSÃO ECONÔMICA PARA AMÉRICA LATINA E CARIBE. Anuário Estatístico 2004. Disponível em: http://www.eclac.cl/badestat/anuario_ 2004/esp.htm. Acesso em: 15 jan. 2006.

COMISSÃO NACIONAL DE COMÉRCIO EXTERIOR. Informe Anual. Buenos Aires: 1999.

COMISSÃO NACIONAL DE COMÉRCIO EXTERIOR. Disponível em: http://www.mecon.gov.ar/cnce/index.htm.

CORREA, Luiz. A visão estratégica brasileira do processo de integração. In: CAMPBELL , J. (Org.). Mercosul entre a realidade e a utopia. Tradução de Maria Luiza X. de A. Borges. Rio de Janeiro: Relume Dumará, 2000.

CÔTÉ, Agathe. Exchange rate volatility and trade: a survey. Working Paper 94-5, Bank of Canada, 1994.

DELL'ARICCIA, Giovanni. Exchange rate fluctuations and trade flows: evidence from the European Union. IMF Staff Papers, v. 46, n. 3, 1999.

EICHENGREEN, Barry. Does Mercosur need a single currency? Working Paper Series, Cambridge, National Bureau of Economic Research - NBER, n. 6821, 1998. 
FERRARI, Lívia. Argentina também quer sobre taxar aço brasileiro. Gazeta Mercantil, São Paulo, p. A5, 17 fev. 1999.

FUNDAÇÃO BANKBOSTON. El traslado de empresas argentinas a Brasil. Boletin Mercosur, Buenos Aires, n. 70, 2000.

FUNDAÇÃO CENTRO DE ESTUDOS DO COMÉRCIO EXTERIOR. Disponível em: http://www.funcex.com.br.

ILLIANO, Cesar. Exportaciones entre sombras. La Nación, Buenos Aires, 14 jan. 1999. Disponível em: http://www.lanacion.com.ar/124484. Acesso em: 11 jul. 2005.

INTERNATIONAL MONETARY FUND. Exchange rate volatility and world trade. Ocasioal Paper n. 28, July. 1984.

LA NACIÓN. Qué se hace con las importaciones. Buenos Aires, 26 jan. 1999. Disponível em: http://www.lanacion.com.ar/217299. Acesso em: 11 jul. 2005.

PEÑA, Felix. As salvaguardas argentinas. Gazeta Mercantil, São Paulo, p. A2, 23 jul. 1999.

ROZEMBERG, Ricardo; SVARZMAN, Gustavo El proceso de integración Argentina-Brasil en perspectiva: el ciclo cambiario y la relación públicoprivada en Argentina. Buenos Aires: Intal, Documento de Divulgação n. 17, 2002.

SARALEGUI, Diego. Los empresários locales temen una avalancha brasileńa. La Nación, Buenos Aires, 17 jan. 1999. Disponível em: http://www.lanacion. com.ar/124836. Acesso em: 11 jul. 2005.

SECRETARIA DE COMÉRCIO EXTERIOR. Disponível em: http:// www.desenvolvimento.gov.br/sitio/secex/depPlaDesComExterior/ indEstatisticas/balComercial.php.

SOARES, Aldo Renato; CHADE, Jamil. Fernando Henrique critica a postura de Buenos Aires. Gazeta Mercantil, São Paulo, p. A6, 29 jul. 1999.

TACHINARDI, Maria Helena. Montadoras argentinas pedem novos incentivos. Gazeta Mercantil, São Paulo, p. A5, 23 abr. 1999a. 
. Argentina pretende prorrogar o regime automotivo. Gazeta Mercantil, Sáo Paulo, p. A4, 14 abr. 1999 b.

URUGUAI. Tribunal Ad Hoc do Mercosul. Laudo arbitral sobre aplicação de medidas de salvaguarda sobre produtos têxteis (res. 861/99) do ministério da economia e obras e serviços públicos. República Federativa do Brasil e República Argentina. Colônia, 10 mar. 2000. Disponível em: http://www.mercosul. gov.br/normativas/default.asp?key=1451. Acesso em: 01 out. 2005.

WISE, Carol. Debates, desempenho e as políticas de escolha política. Revista de Economia Política, v. 21, n. 3 (83), jul./set. 2001. 